\title{
Laranja de polpa vermelha: um estudo físico-químico e sensorial
}

\author{
Bianca Pio Ávila, Gabriela Dutra Alves, Luis Otávio Cardozo, Aline Machado Pereira, \\ Márcia Arocha Gularte, Roberto Pedroso de Oliveira
}

https://doi.org/10.4322/mp.978-65-991393-5-2.c6

\section{Resumo}

Objetivou-se nesse estudo identificar a percepção dos consumidores brasileiros frente ao consumo de laranjas do grupo umbigo de polpa vermelha (Citrus sinensis [L.] Osbeck), bem como gerar informações que auxiliem no seu maior consumo. Realizouse primeiramente a caracterização físico-química da laranja de polpa vermelha cultivar Cara Cara e da laranja de polpa amarela cultivar Navelina, traçando um paralelo entre elas que indicasse os potenciais benefícios nutricionais. A caracterização físicoquímica compreendeu as análises de $\mathrm{pH}$, acidez titulável, sólidos solúveis totais, ácido ascórbico e os compostos bioativos (conteúdo de carotenoides, flavonoides totais e fenóis totais). Ambas as amostras apresentaram características desejáveis de acidez e alto conteúdo de ácido ascórbico (superior a $55 \mathrm{mg} 100 \mathrm{~g}^{-1}$ de porção comestível). A cultivar Cara Cara indicou possuir maiores teores de compostos bioativos. A análise sensorial foi composta pelo teste de aceitação, com escala hedônica de sete pontos, apresentando médias superiores a 6 ("gostei muito" e "gostei moderadamente") na maioria dos atributos das laranjas estudadas e o Teste de Perfil Descritivo, que revelou importantes descritores de diferenças entre as laranjas. Concluindo-se que, estas avaliações foram capazes de indicar importantes informações a serem usadas nas estratégias de marketing a fim de promover o maior consumo de laranjas de umbigo de polpa vermelha, como os valores superiores de compostos bioativos e atributos sensoriais positivos.

Palavras-chave: aceitação, bioativos, Citrus sinensis, consumer insight.

\section{Introdução}

A cultura da laranja (Citrus sinensis [L.] Osbeck) apresenta elevada contribuição social e econômica para o Brasil, considerado o maior produtor mundial, com expressivos números de produção e exportação (MAPA, 2018). As frutas possuem importantes fitonutrientes, como minerais, caretonoides, vitaminas, flavonoides, fenóis e ácidos graxos, e estes compostos têm sido relatados na literatura por possuírem forte capacidade antioxidante (ROUSSOS, 2016).

As laranjas podem ser divididas em dois grandes grupos, em função da coloração da polpa: as laranjas brancas ou claras e as laranjas sanguíneas. As claras são caracterizadas pela cor laranja na polpa e no suco, devido à presença de carotenoides, que são pigmentos com cor que podem variar entre o amarelo e 0 vermelho. Entre esses carotenoides, a presença de licopeno e a maior concentração 
de beta-caroteno caracterizam e propiciam a formação de um subgrupo de laranjas dentro das claras, chamadas de polpa vermelha. As laranjas sanguíneas diferem desse grupo, pois são caracterizadas pela coloração vermelho intensa (violácea) da polpa e do suco, devido à presença do pigmento antocianina (OLIVEIRA et al., 2015). Segundo Roussos (2016) os principais critérios na escolha de uma cultivar de uma variedade específica, além das características da própria planta, são principalmente o tamanho da fruta, seu sabor, a facilidade de descascar e o conteúdo de suco. Novos critérios estão sendo adicionados, sobretudo em relação à funcionalidade do fruto consumido e do conteúdo de compostos nutritivos. Atualmente, as propriedades antioxidantes das frutas cítricas estão se tornando um fator importante na determinação da compra pelo consumidor (LOIZZO et al. 2018).

No Brasil, as variedades de laranjeiras de umbigo têm importância histórica, pois tiveram sua origem no Estado da Bahia de uma mutação da laranjeira 'Seleta', sendo conhecida aqui como laranjeira 'Bahia', 'Baianinha' e, em outros países, como 'Washington Navel'. A cultivar 'Navelina' não tem sementes, é fácil de descascar, polpa doce, suculenta, ácida e de cor amarelo, apreciada para o consumo in natura. É considerada uma importante cultivar cítrica e produzida apenas no Brasil, sendo muito apreciada pelos consumidores em geral (OLIVEIRA et al., 2010).

A laranja cultivar 'Cara Cara' surgiu por mutação espontânea da cultivar Washington Navel, caracterizada como uma laranja do grupo 'umbigo', com coloração vermelho intensa da polpa e do suco. Essa cultivar foi introduzida pela Empresa Brasileira de Pesquisa Agropecuária (EMBRAPA) e representa uma novidade no mercado brasileiro, que não possui o hábito de consumir frutas cítricas de polpa vermelha (OLIVEIRA et al., 2015).

Considerando a importância da produção de citrus no Brasil, objetivou-se no presente estudo comparar os compostos bioativos, caracterizar os parâmetros físico-químicos e sensoriais da laranja de polpa vermelha e de polpa amarela, a fim de aumentar o consumo de laranjas e assim gerar informações que auxiliem nas estratégias de marketing e comercialização, expondo seus benefícios nutricionais.

\section{Materiais e Métodos}

As laranjas do grupo Umbigo cv. Cara Cara e cv. Navelina consideradas nesse estudo foram colhidas entre junho e julho de 2018. Três lotes diferentes foram utilizados, fornecendo uma amostra representativa de frutas oferecidas aos consumidores em fase de consumo comercial.

Alíquotas das polpas frescas foram homogeneizadas e submetidas a congelamento e processo de secagem por liofilização. Após, as frutas foram congeladas a uma temperatura de $-20^{\circ} \mathrm{C}$ e posteriormente liofilizadas em liofilizador (Liobrás - L101), sendo, em seguida, trituradas em moinho de bolas (Marconi - MA 350) e armazenadas em ultra- freezer $\left(-80^{\circ} \mathrm{C}\right)$ até o momento das análises dos compostos bioativos.

Para as análises de determinação de $\mathrm{pH}$, acidez total, sólidos solúveis totais e análise sensorial, foram utilizadas frutas frescas.

\subsection{Parâmetros físico-químicos}

\subsubsection{Determinação de pH}

A análise foi realizada conforme a metodologia descrita pelo Instituto Adolf Lutz (2008). Para tal, foram pesadas $10 \mathrm{~g}$ de amostra, in natura, e dissolvidas em $100 \mathrm{~mL}$ 
de água deionizada, agitando em agitador magnético. Após, procedeu-se a leitura direta em pHmetro. A análise foi realizada em triplicata.

\subsubsection{Acidez total ou acidez titulável}

A análise foi realizada conforme metodologia descrita pelo Instituto Adolf Lutz (2008) com adaptações. Com o auxílio de uma centrífuga doméstica, foi preparado um suco a partir das frutas in natura. Foram transferidos $10 \mathrm{~mL}$ das amostras para béquer e as

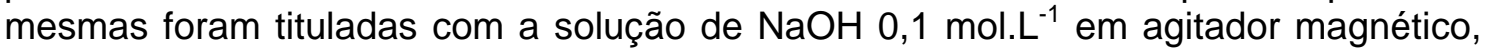
até $\mathrm{pH}$ 8,1 (titulação potenciométrica). A análise foi realizada em triplicata.

\subsubsection{Determinação de sólidos solúveis ( ${ }^{\circ}$ Brix)}

A análise foi realizada conforme a metodologia descrita pelo Instituto Adolf Lutz (2008). As amostras $(10 \mu \mathrm{L})$ foram adicionadas ao prisma do refratômetro (modelo DIV-0070.00). Foi realizada a leitura direta no mesmo, em triplicata.

\subsection{4. Ácido Ascórbico}

Para determinação do ácido ascórbico, as amostras de laranjas foram analisadas pelo método colorimétrico como uso do indicador DCFI (2,6-diclorofenol-indofenol), segundo Oliveira, Godoy e Prado (2010) com os resultados expressos em mg.100 mL ${ }^{1}$ de suco.

\subsection{Compostos bioativos}

\subsubsection{Conteúdo de Carotenoides}

A determinação de carotenoides nas laranjas foi realizada de acordo com Lee (2001). Utilizou-se um espectrofotômetro UV/vis 17000 Shimadzu para medições de absorbância a $450 \mathrm{~nm}$ para o $\beta$-caroteno. O conteúdo total de carotenoides foi expresso como equivalente de $\beta$-caroteno.

\subsubsection{Flavonoides Totais}

As amostras $(2,5 \mathrm{~g})$ foram extraídas em Soxhlet e refluxados com metanol durante mais de $12 \mathrm{~h}$ a $85^{\circ} \mathrm{C}$. O extrato foi evaporado em evaporador rotativo a vácuo $\left(40{ }^{\circ} \mathrm{C}\right)$ e depois dissolvido com metanol (WANG; CHUANG; HSU, 2008). O extrato (1 mL) foi avolumado para $10 \mathrm{~mL}$ com $\mathrm{NaNO}_{2}$ a $5 \%$ e a mistura foi mantida durante 6 min à temperatura ambiente. Adição de $0,3 \mathrm{~mL}$ de $10 \% \mathrm{Al}\left(\mathrm{NO}_{3}\right)_{3}$ à mistura, que foi incubada por 6 min novamente, seguiu-se a adição de $4 \mathrm{~mL}$ de $\mathrm{NaOH} 1 \mathrm{~mol} . \mathrm{L}^{-1}$ e de metanol. Depois de incubar para 15 min à temperatura ambiente para desenvolvimento de cor, a absorbância a $510 \mathrm{~nm}$ foi medida. Os flavonoides totais foram expressos como equivalentes de rutina. A curva de calibração da rutina foi preparada em soluções etanólicas com o mesmo procedimento.

\subsubsection{Fenóis Totais}

As amostras (100 $\mu \mathrm{L}$ de extrato) reagiram com $500 \mu \mathrm{L}$ de reagente Folin-Ciocalteu,1,5 $\mathrm{mL}$ de $\mathrm{Na}_{2} \mathrm{CO}_{3}$ a $20 \%(\mathrm{p} / \mathrm{v})$ e $\mathrm{H}_{2} \mathrm{O}$. Após $2 \mathrm{~h}$ de incubação a $25^{\circ} \mathrm{C}$, a absorbância foi medida a $760 \mathrm{~nm}$ e comparada com curva de calibração de ácido gálico e expressa em $\mathrm{mg}$ de equivalentes de ácido gálico (GAE, mg. $\left.\mathrm{L}^{-1}\right)$. Os dados são apresentados como a média das análises em triplicata (XU et al., 2008). Os fenóis totais foram expressos em mg. $\mathrm{L}^{-1}$ de ácido gálico. 


\subsection{Análise Sensorial}

Todos os experimentos realizados neste trabalho foram aprovados pelo Comitê de Ética em Pesquisa da Universidade Federal de Pelotas, Brasil, sob o número CAAE 76628617.0.0000.5317.

\subsubsection{Teste de Aceitação (Escala Hedônica)}

A análise sensorial utilizando o teste de aceitação (GULARTE, 2009) foi realizada no Laboratório de Análise Sensorial da Universidade Federal de Pelotas e contou com 100 voluntários (estudantes, professores e servidores) que consomem regularmente laranjas. As amostras de laranjas foram codificadas com três dígitos aleatórios, servidas em pratos de porcelana branca, inteiras e cortadas em pedaços de $10 \mathrm{~g}$, para que o avaliador pudesse visualizar as amostras como um todo e também prová-las. A ficha sensorial continha os seguintes atributos: impressão global, aparência externa da laranja, cor da casca, cor interna, aparência interna, tamanho, sabor característico, aroma, suculência, doçura e acidez, que foram analisados usando uma escala hedônica de 7 pontos ( 7 - gostei muito, 1 - desgostei muito).

\subsubsection{Perfil de Atributos}

Para avaliação de atributos sensoriais, 20 avaliadores treinados foram recrutados, entre estudantes e servidores da universidade. Os avaliadores foram informados sobre os procedimentos da pesquisa e o termo de consentimento livre e esclarecido foi fornecido juntamente com a ficha sensorial.

Os avaliadores foram treinados em três sessões de 15 minutos. Os termos foram selecionados avaliando a frequência com que apareceram, e sinônimos ou termos raramente citados de forma consensual foram eliminados.

No total, onze termos (impressão global, aparência externa, cor da casca, cor interna, aparência interna, tamanho, odor, sabor, suculência, doçura e acidez) foram avaliados.

O método descritivo (GULARTE, 2009) foi utilizado nas laranjas frescas in natura, utilizando fichas com a escala não estruturada de nove pontos. As amostras foram codificadas com três dígitos aleatórios. Dez gramas das amostras foram servidos individualmente aos avaliadores em pratos de porcelana. O teste foi realizado em cabines individuais com luz branca, livre de ruídos e odores.

\subsubsection{Questionário sobre padrão de consumo}

Os avaliadores que participaram do teste de aceitação e do perfil de atributos foram convidados a responder sobre sua decisão na hora de comprar ou não laranjas de polpa vermelha, com as seguintes opções de resposta: gênero, tipo de laranja que consome, horário e frequência de consumo de laranjas e sua relação com a saúde, e na decisão de compra quais fatores leva em consideração em comprar laranjas de polpa vermelha (disponibilidade, preço, aparência externa, tamanho, alteração genética/transgenia).

\subsection{Análise estatística}

Os testes das análises físico-químicas foram realizados em triplicata $(n=3)$ e os resultados apresentados como a média das três repetições. Os dados foram analisados por análise de variância (ANOVA) ao nível de confiança de 95\%. 
O teste de aceitação da análise sensorial foi analisado através da frequência relativa de cada atributo $(n=100)$. Foi aplicada a análise de correspondência (CA) nos resultados do teste de Perfil de Atributos, que explica a relação entre os atributos e as amostras (B - laranja Navelina e C - laranja Cara Cara), para obter um padrão de percepção do consumidor. A Análise dos Componentes Principais (PCA) foi realizada na matriz de covariância das questões aplicadas aos avaliadores, para obter um mapa do padrão de consumo.

\section{Resultados e Discussão}

\subsection{Parâmetros físico-químicos}

Os parâmetros físico-químicos das laranjas podem ser observados na Tabela 1. As amostras de laranjas estudadas apresentaram diferenças significativas nos valores de pH. Além disso, a cultivar Navelina $(3,97)$ apresentou valores inferiores $(4,31)$ aos encontrados por Sombra et al. (2018) que também estudaram variedades de coloração amarela e superiores as laranjas do tipo Valencia, reportados por Pereira, Machado e Costa (2014).

Tabela 1. Parâmetros físico-químicos, vitamina $C$ e compostos bioativos das laranjas Cara Cara e Navelina.

\section{Cultivares de laranjas}

\section{Cara Cara Navelina}

\section{Análises}

$\mathrm{pH}$

$3,18 \pm 0,01$

$3,97 \pm 0,03$

Acidez titulável total $\left(\mathrm{g} \cdot \mathrm{L}^{-1}\right)$

$12,11 \pm 0,12$

$9,88 \pm 0,02$

Sólidos solúveis totais ( ${ }^{\circ}$ Brix)

$17,21 \pm 0.13$

$11,98 \pm 0,16$

Vitamina C (mg.100mL $\left.{ }^{-1}\right)$

$60,90 \pm 0.28$

$58,45 \pm 0,41$

Carotenoides totais $\left(\mathrm{mg} \cdot \mathrm{g}^{-1} \mathrm{db}\right)$

$0,51 \pm 0,02$

$0,47 \pm 0,03$

Flavonoides totais $\left(\mathrm{mg} \cdot \mathrm{L}^{-1}\right)$

$189,95 \pm 1,08$

$177,62 \pm 1,11$

Fenóis totais (mg GAE. $L^{-1}$ )

$196,74 \pm 0,4$

$110,03 \pm 0,5$

médias \pm desvio padrão $(n=3)$. ns: não significativo pelo teste $t(p \leq 0,05)$.

Com relação à acidez titulável a variedade de polpa vermelha encontra-se dentro dos valores encontrados por El-Sayed et al. (2007). Entre as propriedades físico-químicas, o conteúdo de sólidos solúveis totais (SST) é importante parâmetro na indústria de frutas. O conteúdo de SST dessa cultivar Cara Cara (11,98 ${ }^{\circ}$ Brix) foi superior a cultivar de polpa amarela. Essas variações na concentração de sólidos solúveis totais, pH e 
acidez são características, assim como tamanho e forma da fruta, são explicadas devido a influência que sofrem pelo porta-enxerto (CONTINELLA et al., 2018).

O ácido ascórbico normalmente é a vitamina que o consumidor melhor sabe associar o alimento com a saudabilidade, prova disso que rótulos de sucos sempre enfatizam o conteúdo de vitamina C (CAl et al., 2011). Nesse estudo, verificou-se maiores teores na laranja de polpa vermelha Cara Cara $\left(60,90 \mathrm{mg} .100 \mathrm{~mL}^{-1}\right)$, sendo que a laranja de coloração amarela diferiu significativamente $(p \leq 0.05)$. Segundo a Agência de Vigilância Sanitária do Brasil (BRASIL, 2005) a recomendação diária de vitamina C para adultos é de $45-80 \mathrm{mg}^{-\mathrm{dia}^{-1}}$ o que indica que ambas cultivares estariam suprindo com a necessidade diária.

\subsection{Compostos bioativos}

Os resultados do presente estudo confirmam (Tabela 1) o maior teor de carotenoides na laranja de polpa vermelha em comparação com a cultivar Navelina. Lu et al. (2017) estudaram o perfil de carotenoides de laranjas sanguíneas de cinco regiões da China e concluíram que os teores e a composição dos carotenoides sofrem influência da temperatura e condições ambientais locais.

A respeito do conteúdo total de flavonoides $\left(189,95 \mathrm{mg} \cdot \mathrm{L}^{-1}\right)$ e fenóis totais $(196,74 \mathrm{mg}$ CAE. $\left.L^{-1}\right)$, a cultivar Cara Cara apresentou maiores valores $(p \leq 0,05)$ em comparação a Navelina. O conhecimento de compostos com capacidade antioxidante é um indicador importante da qualidade nutricional de um alimento, devido sua eficácia em prevenir doenças crônicas (CAO; CHEN; XIAO, 2011; OLABINJO et al., 2017).

O conteúdo de flavonoides totais e fenóis totais de ambas cultivares foram superiores ao encontrado por Kafkas et al. (2009), estes autores analisaram variedades sanguíneas, encontrando variações de 121-239 mg. $\mathrm{L}^{-1}$ em flavonoides e de 441-527 mg. $\mathrm{L}^{-1}$ em fenóis totais. Kirinus et al. (2018) estudaram as laranjas Navelinas e reportaram valores de 108,94 mg GAE. $\mathrm{L}^{-1}$ em conteúdo fenólico. O conteúdo e o perfil de compostos bioativos podem variar entre cultivares, pois, a atividade de enzimas $\mathrm{e}$ ativadores transcriptores de sua síntese sofrem influência da umidade relativa do ar (ITHAL; REDDY, 2004). A hesperidina e a naringina são flavonoides encontrados predominantemente em laranjas e toranjas e sua atividade antioxidante e de transporte das células do sangue são reportadas (CAO; CHEN; XIAO, 2011).

\subsection{Análise sensorial}

\subsubsection{Teste de Aceitação (Escala hedônica)}

A Figura 1 está apresentando o histograma dos resultados obtidos para a frequência hedônica dos atributos das laranjas Cara Cara e Navelina.

Pode-se verificar que para a laranja de polpa amarela Navelina, a porcentagem de provadores que "gostaram muito" (nota 7) apresentou os maiores resultados, com frequências de 62,9\% para a acidez e sabor característico, 51,40\% para a aparência externa, 31,40\% para a impressão global. Ressalta-se que apenas para o atributo suculência os provadores assinalaram 'desgostei' $(5,70 \%)$ na escala hedônica.

Quanto à doçura e o odor, as frequências foram maiores para os termos 'gostei muito' e 'gostei moderadamente', apresentando valores acima de $97 \%$ e $94 \%$ respectivamente. 
$\mathrm{Na}$ impressão global ambas laranjas foram bem aceitas sensorialmente. A aparência externa e cor da casca obtiveram frequências próximas ao termo 'gostei muito', sendo a cultivar Cara Cara com maior valor. Segundo Oliveira et al. (2010) nem sempre há relação direta da cor externa para a interna em laranjas de polpa vermelha, geralmente essa relação é mais perceptível em laranjas sanguíneas, fato esse que pudemos observar com a análise sensorial, em que os consumidores deram notas superiores na cor externa (casca) para a cultivar Cara Cara e notas menores para a cor interna (polpa) demonstrando que a cor laranja/amarela de polpa é mais aceita na visão do consumidor que a cor vermelha, assim como no atributo 'aparência interna', como foi observado na laranja Navelina.

\section{Laranja Navelina}

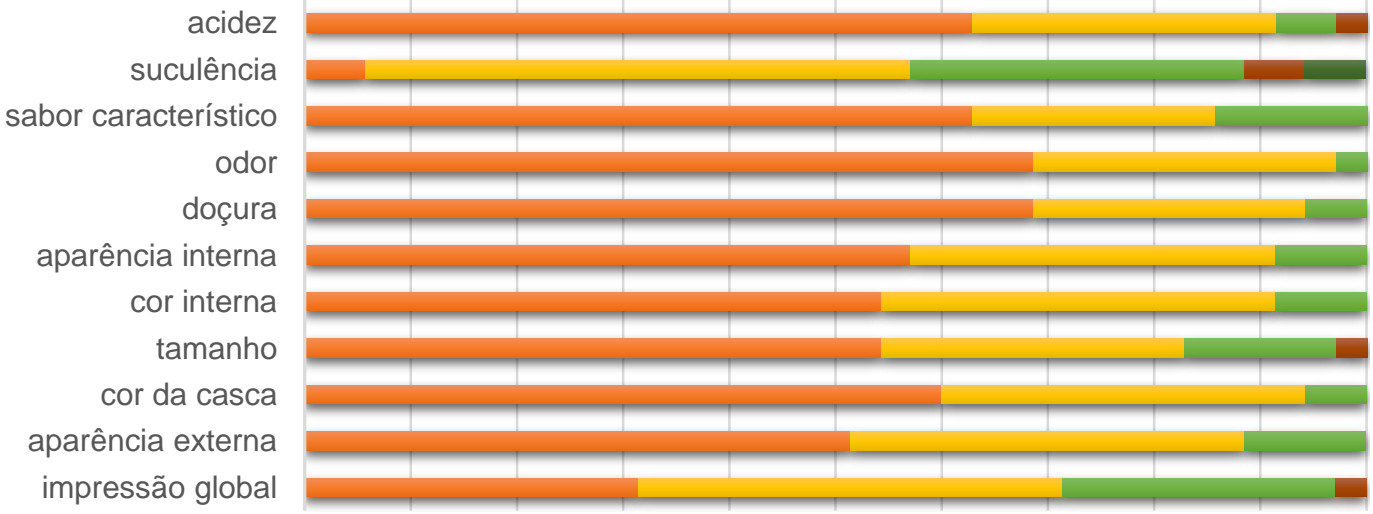

0,00\% 10,00\% 20,00\% 30,00\% 40,00\% 50,00\% 60,00\% 70,00\% 80,00\% 90,00\% 100,00\%
- Gostei muito
- Gostei moderadamente
u Gostei

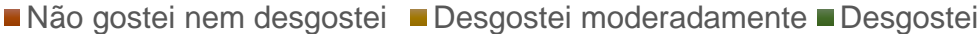
- Desgostei muito

Laranja Cara Cara

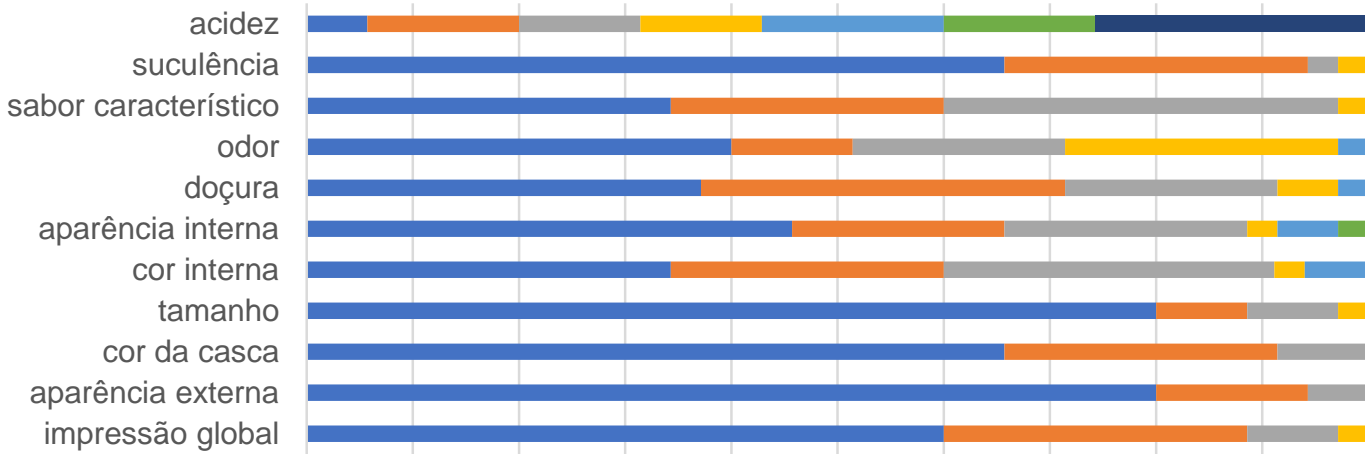

0,00\% $10,00 \% \quad 20,00 \% \quad 30,00 \% \quad 40,00 \% \quad 50,00 \% \quad 60,00 \% \quad 70,00 \% \quad 80,00 \% \quad 90,00 \% 100,00 \%$
- Gostei muito
- Gostei moderadamente
a Gostei

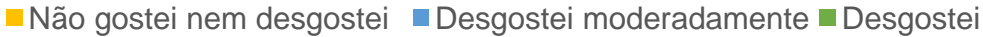
- Desgostei muito

Figura 1. Teste de Aceitação com escala de 7 pontos para os atributos sensoriais das laranjas das cultivares Cara Cara e Navelina. 
No atributo 'sabor característico' verificou-se que a cultivar Navelina teve uma aceitação maior. Observações feitas pelos consumidores nas fichas sensoriais indicaram que a laranja de polpa vermelha não possuía um sabor intenso como o esperado, assim como para o atributo 'odor'. A acidez (25,7\% desgostei muito) também não obteve aceitação tanto quanto a laranja de polpa amarela (62,9\% gostei muito), atributo este, desejável pelos consumidores para as laranjas desse grupo 'umbigo'.

A cultivar Cara Cara foi considerada mais suculenta, apresentando frequências de 65,71 \% (gostei muito), demonstrando ser um parâmetro muito positivo, principalmente para a indústria de sucos. Moufida e Marzouk (2003) reportam que as laranjas sanguíneas e as de polpa vermelha são aquelas que geram a maior porcentagem de suco, além de possuírem maior concentração de açúcares, não obstante, com relação ao composto limoneno (composto de maior importância para compor o aroma), os teores são menores.

\subsubsection{Perfil de Atributos}

A análise de correspondência realizada na matriz de covariância das pontuações médias dos descritores avaliados pelos consumidores na análise descritiva está representada na Figura 2. Os dois componentes foram capazes de explicar 97,26\% das variações, sendo a Dominância 1 (D1) responsável por 49,94\% da variação e a Dominância 2 (D2) por 47,32\%.



Figura 2. Análise de Correspondência sobre os atributos avaliados no teste de Perfil de Atributos para as laranjas Cara Carca (C) e laranja Navelina (N).

Observa-se que o eixo D1 está positivamente associado aos atributos de acidez, odor, doçura e sabor para a laranja Navelina. A combinação desses dois atributos, conhecido como 'flavour' possui grande influência na aceitação de citrus e que por 
consequência possuem relação com o conteúdo de sólidos totais, a acidez e compostos voláteis conforme estudos de Obenland, Campisi-Pinto e Arpaia (2018).

O eixo D2 apresentou associações principalmente com os atributos da laranja Cara Cara, demonstrando claramente que os avaliadores fizeram associações distintas às da laranja Navelina. Segundo Saunt (2000) as laranjas do tipo 'navel' possuem um sabor doce e agradável, no entanto detecta-se um amargor retardado, devido a liberação de limonina.

A acidez por sua vez, esteve distante dos demais atributos, assim como a percepção observada no teste de aceitação com consumidores, indicando que a acidez não foi um parâmetro significativo para a laranja de polpa vermelha. O que pode ser confirmado pelos valores encontrados nas análises químicas de $\mathrm{pH}$ para ambas as laranjas.

\subsubsection{Padrão de consumo}

A Figura 3 representa o padrão de consumo de laranjas e em especial, de laranjas de polpa vermelha, relativas ao questionário aplicado aos consumidores.

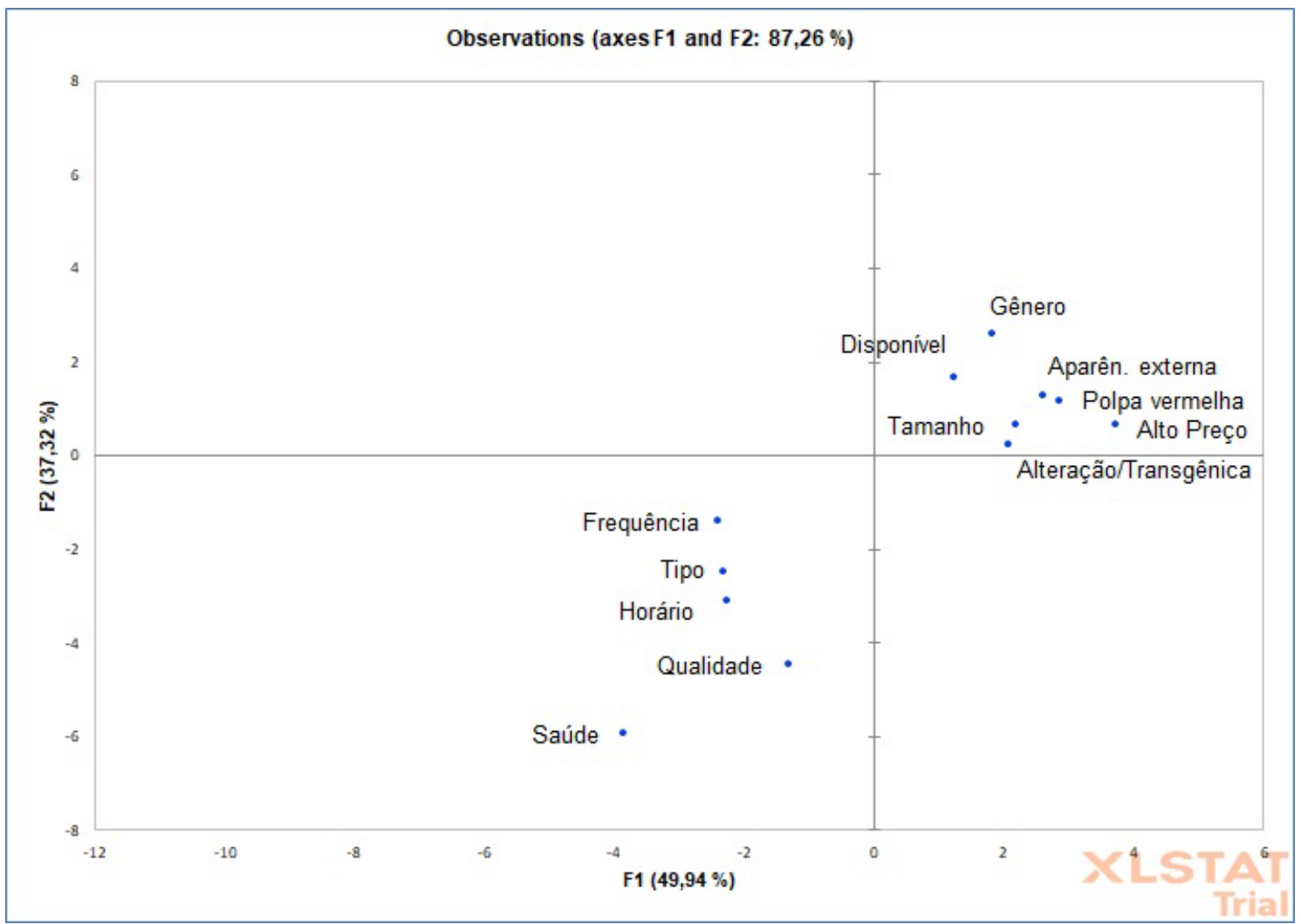

Figura 3. Biplot da análise de componentes principais das questões relativas ao consumo de laranjas.

Os resultados obtidos nos fatores (F1 e F2) demonstraram significativo ajuste dos dados (87,26\%). O fator 1 foi capaz de correlacionar as questões relativas à frequência de consumo, tipo de laranja, horário de consumo, qualidade das frutas e saúde.

Enneking, Neumann e Henneberg (2007) explicitam que a decisão de compra do consumidor vai muito além de respostas hedônicas, ou seja, é importante salientar que 
a qualidade e a decisão de compra de um produto nem sempre está atrelada ao sabor, por isso, deve-se pensar na qualidade da fruta como um todo, a fim de se conquistar 0 consumidor.

O comportamento do consumidor em relação a alimentos funcionais ou a presença de antioxidantes é crescente, pois a população vê a sua relação à manutenção da saúde e tratamento de diversas doenças (KÜSTER-BOLUDA; VIDAL-CAPILLA, 2017). Conforme o questionário aplicado, os consumidores assinalaram sua preferência em consumir laranjas durante todo o dia, e não em horários específicos, o que indica, conhecerem os benefícios nutricionais dessa fruta.

Quanto ao tipo de laranja consumida, as de maior destaque são as laranjas do grupo umbigo, segundo a Sociedade Brasileira de Fruticultura (SBF, 2018), pois geralmente não possuem sementes, são de fácil descasque, apresentam sabor adocicado e acidez equilibrada, no entanto, as laranjas de umbigo de polpa vermelha não entram nessa preferência do consumidor, como pode ser observado pelo fator 2 (F2) do gráfico.

O fator 2 agrupa as questões relativas a gênero, disponibilidade das laranjas de polpa vermelha no comércio, tamanho das frutas, aparência externa, preço, conhecimento dos consumidores sobre as laranjas de polpa vermelha e percepção sobre alterações genéticas e transgenia.

Podemos observar que diferenças de gênero influenciam no comportamento de compra. Segundo Smith et al. (2013) as mulheres são tipicamente responsáveis pelo preparo da refeição em casa, com isso é importante que as estratégias de marketing sejam mais direcionadas às mulheres, as quais possuem maior atitude de compra em relação a alimentos funcionais (KÜSTER-BOLUDA; VIDAL-CAPILLA, 2017).

Observou-se durante a pesquisa que $73 \%$ dos participantes do questionário nunca haviam consumido ou comprado laranjas de polpa vermelha, que respondem os motivos que levam o consumidor a não efetuar a compra. No caso do estudo em questão, verificou-se que esse tipo de laranja não era encontrado com facilidade nos estabelecimentos comerciais, ou quando era, o valor era bem superior aos demais tipos de laranjas.

Além disso, os consumidores associam a cor vermelha a alterações genéticas ou transgênicas. Essa característica que gera grande valor nutricional e que traz a coloração vermelha, respectiva a altos teores de carotenoides, gera pensamentos errôneos e de desconfiança nos consumidores, o que demonstra claramente a falta de informação das pessoas. Conforme Castro, Young e Lima (2014) essa questão aponta para uma preocupação do consumidor com os riscos que eles podem trazer à mesa estando contaminados por agentes químicos ou biológicos.

Com isso, podemos sugerir que o marketing deve acontecer de maneira mais prática, através de degustações em feiras, supermercados, escolas, pois somente a imagem da laranja de polpa vermelha pode trazer insegurança ao consumidor que não a conhece. O uso de termos como vitamina C, fibras, antioxidantes e saudável demonstra um nicho a ser explorado como forma de divulgação.

\section{Conclusão}

Este estudo mostrou o alto valor nutricional da laranja de umbigo de polpa vermelha cultivar Cara Cara, assim como da laranja de polpa amarela Navelina, refletindo níveis 
significantes de fenóis, carotenoides e flavonoides, sendo também considerada fonte de vitamina $\mathrm{C}$.

Através da análise sensorial identificamos uma grande aceitação e percepção dos consumidores e avaliadores em relação a maioria dos atributos estudados, assim como, foi possível mensurar as principais características que devem ser consideradas em estratégias de marketing pelas indústrias, produtores e varejistas, que queiram incrementar o consumo de citrus de polpa vermelha, entre elas a maior disponibilidade no comércio, o preço acessível, a qualidade e a divulgação dos benefícios nutricionais.

\section{Referências}

BRASIL. Ministério da Saúde. Agência Nacional de Vigilância Sanitária. Resolução RDC $n^{\circ}$ 269, de 22 de setembro de 2005: aprova o Regulamento Técnico sobre a Ingestão Diária Recomendada (IDR) de Proteína, Vitaminas e Minerais. Diário Oficial da República Federativa do Brasil, Brasília, DF, 2005.

CAI, Y. et al. MeJA regulates enzymes involved in ascorbic acid and glutathione metabolism and improves chilling tolerance in loquat fruit. Postharvest Biology $\begin{array}{llllll}\text { Technology, } & \text { v. } & 59, & \text { n. } & 3, & \text { p. }\end{array}$ https://doi.org/10.1016/j.postharvbio.2010.08.020.

CAO, H.; CHEN, L.; XIAO, J. Binding Citrus flavanones to human serum albumin: effect of structure on affinity. Molecular Biology Reports, v. 38, n. 4, p.2257-2262, 2011. https://doi.org/10.1007/s11033-010-0356-z.

CASTRO, B. S.; YOUNG, C. E. F.; LIMA, G. R. A percepção pública de risco alimentar e os organismos geneticamente modificados no Brasil. Estudos Sociedade e Agricultura, v. 22, n. 1, p. 164-192, 2014. Disponível em: <https://revistaesa.com/ojs/index.php/esa/article/view/472>. Acesso 28 dez. 2020.

CONTINELLA, A. et al. Influence of different rootstocks on yield precocity and fruit quality of 'Tarocco Scirè' pigmented sweet orange. Scientia Horticulturae, v. 230, p. 62-67, 2018. https://doi.org/10.1016/j.scienta.2017.11.006.

EL-SAYED, S. A. G. et al. Yield and fruit quality of Washington navel orange as affected by sour orange and volkamer lemon rootstocks. The Journal of Agricultural Science, v. 32, n. 11, p. 9217- 9226, 2007.

ENNEKING, U.; NEUMANN, C.; HENNEBERG, S. How important intrinsic and extrinsic product attributes affect purchase decision. Food Quality and Preference, v. 18, p.133-138, 2007. https://doi.org/10.1016/j.foodqual.2005.09.008.

GULARTE, M. A. Manual de análise sensorial de alimentos. Editora da UFPel: Pelotas, 2009. 109p.

INSTITUTO ADOLF LUTZ. Métodos físico-químicos para análise de alimentos. Coordenadores Odair Zenebon, Neus Sadocco Pascuet e Paulo Tiglea - São Paulo: Instituto Adolfo Lutz, 2008. 1020 p.

ITHAL, N.; REDDY, A. R. Rice flavonoid pathway genes, OsDfr and OsAns, are induced by dehydration, high salt and $A B A$, and contain stress responsive promoter elements that interact with the transcription activator, OsC1-MYB. Plant Science, v. 166, n. 6, p. 1505-1513, 2004. https://doi.org/10.1016/j.plantsci.2004.02.002. 
KAFKAS, E. et al. Chemical composition of blood orange varieties from Turkey: a comparative study. Pharmacognosy Magazine, v. 5, n. 20, p. 329-335, 2009. https://doi.org/10.4103/0973-1296.58155.

KIRINUS, M. B. M. et al. "Navelina" oranges submitted to pre-harvest resistance inducers. Acta Scientiarum. Agronomy, v. 40, n. 1, p. 364-395, 2018. http://dx.doi.org/10.4025/actasciagron.v40i1.39465.

KÜSTER-BOLUDA, I.; VIDAL-CAPILLA, I. Consumer attitudes in the election of functional foods. Spanish Journal of Marketing-ESIC, v. 21, p. 65-79, 2017. https://doi.org/10.1016/j.sjme.2017.05.002.

LEE, H. S. Characterization of carotenoids in juice of red navel orange (Cara Cara). Journal of Agricultural and Food Chemistry, v. 49, p. 2563-2568, 2001. https://doi.org/10.1021/jf001313g.

LOIZZO, M. et al. Investigating the in vitro hypoglycaemic and antioxidant properties of Citrus $\times$ clementina Hort. juice. European Food Research and Technology, v. 244, p. 523-534, 2018. https://doi.org/10.1007/s00217-017-2978-z.

LU, Q. et al. Carotenoid profiling of red navel orange "Cara Cara" harvested from five regions in China. Food Chemistry, v. 232, p. 788-798, 2017. https://doi.org/10.1016/j.foodchem.2017.04.064.

MAPA- Ministério da Agricultura, Pecuária e Abastecimento. Laranja (2018). Disponível em: http://www.agricultura.gov.br/assuntos/politica-agricola/todaspublicacoes-de politica-agricola/sumarios-executivos-de-produtos-agricolas/laranja1.pdf/view. Acesso em: 12 dez. 2018.

MOUFIDA, S., MARZOUK, B. Biochemical characterization of blood orange, sweet orange, lemon, bergamot and bitter orange. Phytochemistry, v. 62, n. 8, p. 12831289, 2003. https://doi.org/10.1016/s0031-9422(02)00631-3.

OBENLAND, D.; CAMPISI-PINTO, S.; ARPAIA, M. L. Determinants of sensory acceptability in grapefruit. Scientia Horticulturae, v. 231, p. 151-157, 2018. https://doi.org/10.1016/j.scienta.2017.12.026.

OLABINJO, O. O. et al. Analysis of physical and chemical composition of sweet orange (Citrus sinensis) peels. International Journal of Environment Agriculture and Biotechnology, v. 2, n. 4, p.2201-2206, 2017. https://doi.org/10.22161/ijeab/2.4.80.

OLIVEIRA, R. P. et al. Produção orgânica de citros no Rio Grande do Sul. $2^{a}$ edição, Pelotas, Brasil: Embrapa Clima Temperado, 2010. 296p.

OLIVEIRA, R. G.; GODOY, H. T.; PRADO, M. A. Optimization of a colorimetric method to determine ascorbic acids in fruit jelly. Ciência e Tecnologia de Alimentos, Campinas, v. 30, n. 1, p. 244-249, 2010. https://doi.org/10.1590/S010120612010000100036.

OLIVEIRA, R. P. et al. Coleção de citros da Embrapa Clima Temperado (Ed.) Pelotas: Embrapa Clima Temperado, Brasil, 2015, 33 p.

PEREIRA, G. S.; MACHADO, F. L. C.; COSTA, J. M. C. Application of coating extends postharvest quality in the 'Valencia Delta' orange during ambient storage. Revista 
Ciência Agronômica, v. 45, n. 3, p. 520-527, 2014. https://doi.org/10.1590/S180666902014000300012.

ROUSSOS, P. A. Orange (Citrus sinensis (L.) Osbeck). In M. Simmonds; V. Preedy (Ed.). Nutritional Composition of Fruit Cultivars (pp. 469-496). Cambridge: Academic Press, 2016.

SAUNT, J. Citrus varieties of the world: An illustrated guide. 2 ed. Norwich: Sinclair International, 2000. 156p.

SBF - Sociedade Brasileira de Fruticultura. Consumo brasileiro de frutas. Disponível em: https://fruticultura.org.br. Acesso em: 20 out. 2018.

SOMBRA, K. et al. Identificação e caracterização físico-química de frutos de laranja de Russas no semiárido cearense, Brasil. Citrus Research \& Technology, v. 39, e1035, 2018. https://doi.org/10.4322/crt.39161.

WANG, Y. C.; CHUANG, Y. C.; HSU, H. W. The flavonoid, carotenoid and pectin content in peels of citrus cultivated in Taiwan. Food Chemistry, v.106, p. 277-284, 2008. https://doi.org/10.1016/j.foodchem.2007.05.086.

$\mathrm{XU}, \mathrm{G}$. et al. Juice components and antioxidant capacity of citrus varieties cultivated in China. Food Chemistry, v. 106, n. 2, p. 545-551, 2008. https://doi.org/10.1016/j.foodchem.2007.06.046.

\section{Autores}

Bianca Pio Ávila ${ }^{1, *}$, Gabriela Dutra Alves², Luis Otávio Cardozo ${ }^{2}$, Aline Machado Pereira $^{3}$, Márcia Arocha Gularte ${ }^{4}$, Roberto Pedroso de Oliveira ${ }^{5}$

1. Curso de Pós-graduação Lato Sensu em Ciência dos Alimentos, Centro de Ciências Químicas, Farmacêuticas e de Alimentos e Departamento de Ciência e Tecnologia Agroindustrial, Universidade Federal de Pelotas, Campus Universitário, Caixa Postal, 354, 96010-900, Pelotas, RS, Brasil.

2. Departamento de Engenharia Química, Instituto Federal Sul-Rio-Grandense, Praça Vinte de Setembro, 455, 96015-360, Pelotas, Brasil.

3. Departamento de Ciência e Tecnologia Agroindustrial, Universidade Federal de Pelotas, Campus Universitário, Caixa Postal, 354, 96010-900, Pelotas, RS, Brasil.

4. Centro de Ciências Químicas, Farmacêuticas e de Alimentos, Universidade Federal de Pelotas, Campus Universitário, Caixa Postal, 354, 96010-900, Pelotas, RS, Brasil.

5. Embrapa Clima Temperado, BR 392 Km78, Pelotas, Brasil.

* Autor para correspondência: biancaagronomia@yahoo.com.br 